exposure to inescapable shock. Psychological Reports, 1956a, 2, 43-49 DINSMOOR, J. A., \& CAMPBELL, S. I Level of current and time between sessions as factors in "adaptation" to shock. Psychological Reports, $1956 \mathrm{~b}, 2$. 441-444.
FOWLER, H., \& TRAPOLD, M. A. Escape performance as a function of delay of reinforcement. Journal of Experimental Psychology, 1962, 63, 464-467.

MCDONALD, S. G., PORTER, J. J., \& MADISON, H. L. Changes following asymptotic instrumental performance as a function of shifts in drive. Psychonomic Science, 1970, 19, 33-34

TRAPOLD, M. A., \& FOWLER, H. Instrumental escape performance as a function of the intensity of noxious stimulation. Journal of Experimental Psychology, 1960,60, 323-326.

\section{Voltage sensing with a unijunction transistor*}

\author{
BARRY GLASGOW \\ University of Minnesota, Minneapolis, Minnesota 55455
}

A voltage-sensing device with very little hysteresis and variable threshold voltage setting is described. Application of the device as a voltage-sensitive variable-duration monostable multivibrator in recording rabbit nictitating membrane conditioning is also discussed.

The device pictured in Fig. 1 is a general-purpose voltage-sensing comparator that closes a relay when the input voltage exceeds a predetermined level (G.E. Transistor Manual, 1964). The duration of the relay closure is variable. from less than $10 \mathrm{msec}$ to greater than $10 \mathrm{sec}$, depending upon the component values selected.

In Fig. 1, Section 1 is the voltage-sensing segment of the circuit and Section 2 is the relay driver. The voltage-sensing function of Section 1 is based upon the operating characteristics of $Q_{1}$, a unijunction transistor. The circuit is basically a relaxation oscillator which puts out a spike waveform at $B_{1}$ whenever the voltage at the emitter (E) of $Q_{\text {, }}$ exceeds the threshold voltage of the transistor. When this occurs, $\mathrm{C}_{1}$ discharges through $\mathrm{D}_{2}$ the transistor, and $R_{1}$ resulting in an elevated voltage across $R_{1}$, having a fast rise time and a slow fall time. Immediately after Capacitor $\mathrm{C}_{1}$ discharges, it starts recharging toward the transistor threshold voltage. For the device depicted, this spike is used to trigger an SCR which operates a relay.

The voltage divider string, $R_{2}, R_{3}$, $R_{4}$, sets the level of voltage at the emitter of $Q_{1}$. This voltage is set to a value below the threshold value of the transistor, such that a small additional positive vol tage at the input is required to raise the voltage at the emitter of $Q_{1}$ above its threshold voltage. The difference between the threshold voltage and the preset voltage from $R_{2}, R_{3}, R_{4}$ determines the magnitude of voltage that will trigger the device. The preset voltage can be set to detect input voltages as small as $10 \mathrm{mV}$. The

*The construction of this device was supported by funds from Grant MH 18053 to Dr. M. A. Trapold. hysteresis is usually less than $5 \mathrm{mV}$. Diodes $D_{1}$ and $D_{2}$, besides providing a discharge path for $\mathrm{C}_{1}$, also protect the input transistor from overload voltages far in excess of the triggering voltage. If a precision potentiometer is used for $R_{3}$, a high degree of sensing resolution can be achieved. It should be noted that so long as the voltage at the emitter of $Q_{1}$ exceeds the threshold voltage, the transistor will continue to put out a series of spike pulses capable of driving a series of flip-flops or triggering an SCR.

The relay driver shown in Section 2 is composed of two SCRs and a unijunction transistor $\left(Q_{2}\right)$. When $\mathrm{SCR}_{2}$ is on, its anode is near ground potential, so that $\psi_{2}$ is inoperative. When the input triggers voltage sensing and Section 2 is the multivibrator. the sensing circuit of Section $1, \mathrm{SCR}_{1}$ is driven into conduction, shutting off $\mathrm{SCR}_{2}$ by discharging the commutating capacitor, $\mathrm{C}_{5}$. As $\mathrm{SCR}_{2}$ turns off, its anode voltage rises toward the positive supply voltage, enabling $Q_{2}$ to act as a relaxation oscillator, similar in operation to $\mathbf{Q}_{1}$. When the voltage on $\mathrm{C}_{6}$ reaches the threshold voltage of $Q_{2}$, it puts out a spike across $R_{10}$, driving $\mathrm{SCR}_{2}$ back into conduction. This action discharges $\mathrm{C}_{c}$ and shuts off $\mathrm{SCR}_{1}$. By adjusting $\mathrm{R}_{8}$, one can control the duration for which $\mathrm{SCR}_{1}$ and the relay are on

The circuit in Fig. 1 includes a simple floating power supply with Zener diode regulation. This particular power supply configuration affords complete freedom of choice in connecting the signal source, since there are no common grounds.

The device described above has been used in the laboratory to sense the output voltage of a Brush oscillograph which was coupled to a rabbit nictitating membrane through a minitorque potentiometer. A response was defined as a $50-\mathrm{mV}$ increase in the output voltage of the oscillograph. Accordingly the voltage sensor was set to trigger when the voltage at the sensor input exceeded $50 \mathrm{mV}$. To avoid false triggering during the

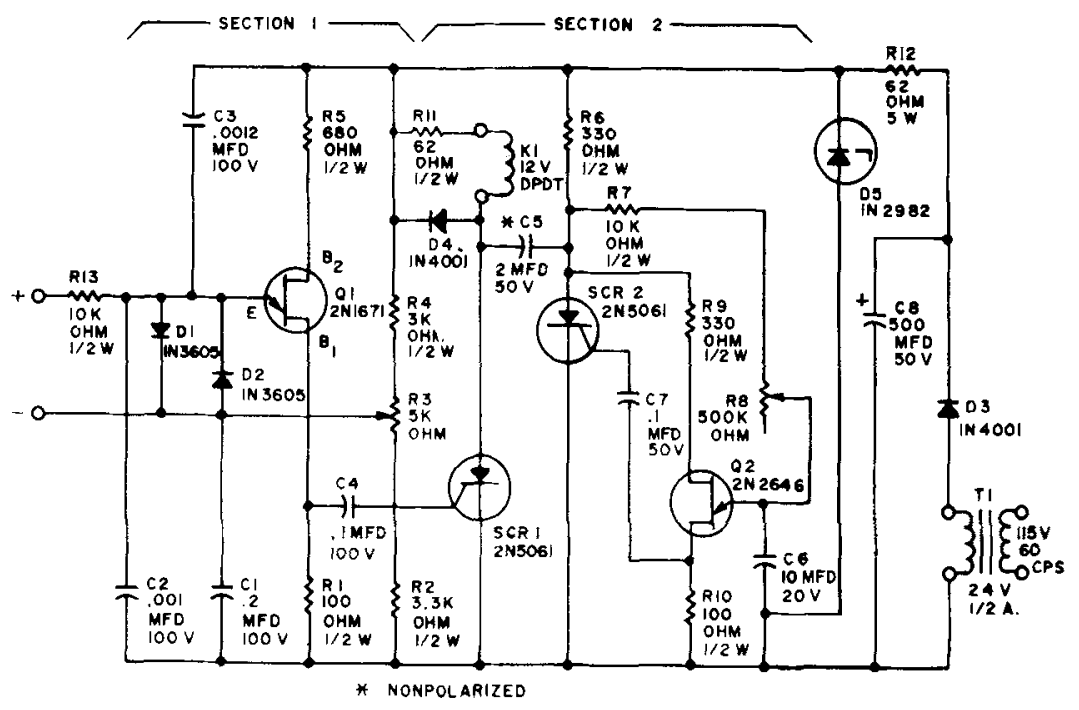

Fig. 1. A voltage-sensitive monostable multivibrator. Section 1 performs the 
Table 1

Parts Price List Derived from the 1971 Allied Electronics Catalogue

\begin{tabular}{|c|c|c|}
\hline \multicolumn{2}{|c|}{ Components } & Unit Price \\
\hline \multicolumn{2}{|c|}{$\mathrm{R1}, \mathrm{R2}, \mathrm{R4}, \mathrm{R5}, \mathrm{R} 6, \mathrm{R} 7, \mathrm{R} 9, \mathrm{R} 10, \mathrm{R} 11, \mathrm{R} 13$ (IRC) } & $\$ .07$ \\
\hline R3 & (Amphenol 10 turn potentiometer) & 5.95 \\
\hline $\begin{array}{l}\text { R8 } \\
\text { R12 }\end{array}$ & $\begin{array}{l}\text { (Ohmite) } \\
\text { (Ohmite) }\end{array}$ & $\begin{array}{r}2.25 \\
.66\end{array}$ \\
\hline $\begin{array}{l}\mathrm{C} 1 \\
\mathrm{C} 2, \mathrm{C3} \\
\mathrm{C} 4, \mathrm{C7} \\
\mathrm{C5} \\
\mathrm{C} 6 \\
\mathrm{C} 8\end{array}$ & & $\begin{array}{r}.78 \\
.34 \\
.60 \\
1.91 \\
.45 \\
1.30\end{array}$ \\
\hline $\begin{array}{l}\text { D1, D2 } \\
\text { D3, D4 } \\
\text { D5 } \\
\text { Q1 } \\
\text { Q2 } \\
\text { SCR1, }\end{array}$ & & $\begin{array}{r}.87 \\
.46 \\
3.96 \\
3.62 \\
1.20 \\
.94\end{array}$ \\
\hline $\begin{array}{l}\text { T1 } \\
\mathbf{K} 1\end{array}$ & (Magnecraft reed relay SPDT) & $\begin{array}{l}4.52 \\
6.83\end{array}$ \\
\hline \multirow{2}{*}{\multicolumn{2}{|c|}{ (Incidental costs, i.e., chassis box, circuit board, etc.) }} & $\begin{array}{r}\$ 40.55 \\
10.00\end{array}$ \\
\hline & & $\$ 50.55$ \\
\hline
\end{tabular}

intertrial interval, the output of the amplifier was gated through a relay which connected it to the voltage sensor at the start of each trial and disconnected it at UCS onset. The output relay of the sensing device was used to increment a counter when the device sensed a response and triggered the relay on. The same relay was used to record the latency of the response by gating the output of a pulse stream generator connected to a printout counter. At the onset of the $\mathrm{CS}$, the pulse stream generator initiated a series of pulses of a known frequency. If a response occurred before onset of the UCS, the relay disconnected the pulse generator from the print counter. The number of pulses recorded by the printout counter provided the duration between CS onset and response initiation.

A parts list for the unit is provided in Table 1.

.E. Transistor manual. (7th ed.) Syracuse: General Electric Co., 1964. Pp. 324-325. 